\title{
Entrectinib: an orally available, selective tyrosine kinase inhibitor for the treatment of NTRK, ROSI, and $A L K$ fusion-positive solid tumors
}

This article was published in the following Dove Press journal:

Therapeutics and Clinical Risk Management

\author{
Dazhi Liu' \\ Michael Offin ${ }^{2}$ \\ Stephen Harnicar ${ }^{1}$ \\ Bob $\mathrm{T} \mathrm{Li}^{2}$ \\ Alexander Drilon² \\ 'Department of Pharmacy, Memorial \\ Sloan Kettering Cancer Center, \\ New York, NY, USA; ${ }^{2}$ Thoracic \\ Oncology Service, Division of Solid \\ Tumor Oncology, Department of \\ Medicine, Memorial Sloan Kettering \\ Cancer Center, Weill Cornell Medical \\ College, New York, NY, USA
}

\begin{abstract}
Entrectinib is a potent small-molecule tyrosine kinase inhibitor that targets oncogenic rearrangements in NTRK, ROS1, and $A L K$. The consolidated results of 2 Phase I trials demonstrated activity in tyrosine kinase inhibitor-naïve patients along with substantial intracranial activity. In ROS1-rearranged lung cancers, entrectinib results in durable disease control and prolonged progression-free survival. The drug is well tolerated and has a safety profile that includes adverse events mediated by on-target tropomyosin-related kinase $\mathrm{A} / \mathrm{B} / \mathrm{C}$ inhibition.
\end{abstract}

Keywords: entrectinib, lung cancer, NSCLC, TRK, ALK, ROS1

\section{Introduction}

Recurrent gene rearrangements are oncogenic drivers in a variety of hematological and solid malignancies. ${ }^{1}$ The discovery and successful targeting of oncogenic fusion kinases have driven a major paradigm shift in oncology; namely, that therapy selection can potentially be based on molecular enrichment instead of purely on histology for some alterations, recognizing that the sensitivity to targeted therapy may be contextdependent for others. Entrectinib is an orally bioavailable small-molecule inhibitor of $N T R K 1 / 2 / 3, R O S 1$, and $A L K .^{2}$ In this review, we focus on the pharmacological profile, safety, and tolerability of this agent. A literature search was performed to identify clinical studies with the investigational agent.

\section{Genomic targets}

Gene fusions involving NTRK1/2/3 and $A L K$ and $R O S 1$ are well-established, clinically actionable drivers of oncogenesis across multiple cancers. ${ }^{3} A L K$ rearrangements are enriched in non-small cell lung cancers (NSCLCs), where they are found in 3\%-4\% of cases, but are also found in other cancer types, including anaplastic large cell lymphoma (ALCL), renal cell, breast, colorectal, and esophageal cancers. ${ }^{4}$ Four targeted therapies (crizotinib, ceritinib, alectinib, and brigatinib) have been approved by 1 or more regulatory agencies for patients with $A L K$-rearranged lung cancers. ROSI fusions are found in 1\%-2\% of unselected NSCLCs, and are also identified in glioblastomas and cholangiocarcinomas, among other tumors. ${ }^{4-10}$ Crizotinib is approved for ROS1-rearranged lung cancers based on improvements in overall response rate (ORR) and progression-free survival (PFS) compared with historical outcomes with chemotherapy. ${ }^{11}$
Correspondence: Alexander Drilon Thoracic Oncology Service, Division of Solid Tumor Oncology, Department of Medicine, Memorial Sloan Kettering Cancer Center, Weill Cornell Medica College, 885 2nd Avenue, I0th Floor, New York, NY I0017, USA

Tel +l 6468884206

Email drilona@mskcc.org 
The tropomyosin-related kinase (TRK) proteins TRKA, TRKB, and TRKC have important roles in the development and function of neurons of the central and peripheral nervous systems. ${ }^{12}$ These are transmembrane glycoproteins that are each encoded by distinct genes: NTRK1, NTRK2, and NTRK3, respectively. ${ }^{3,12}$ Neutrophin-mediated receptor dimerization is initiated by the binding of 1 of 4 neurotrophin family ligands: nerve growth factor (NGF), brain-derived neurotrophic factor (BDNF), neurotrophin-3 (NT-3) and NT-4 to 1 or more TRK receptors. Binding then leads to autophosphorylation of tyrosine residues in the intracellular domain and the activation of several signal cascades, including the mitogen-activated protein kinase, phosphatidylinositol-3kinase, and Janus kinase-signal transducer and activator of transcription pathways. ${ }^{12}$

Genomic alterations involving NTRK include chromosomal rearrangements, point mutations, in-frame deletions and splice variants; ${ }^{13}$ however, only NTRK fusions are widely recognized to be clinically targetable. These fusions have been identified to be the predominant drivers of certain rare tumor types, such as mammary secretory carcinoma, mammary analog secretory carcinoma (MASC), and congenital fibrosarcoma. ${ }^{13}$ Intriguingly, the frequency of NTRK fusions is much lower $(<1 \%)$ in a wider array of common cancers, such as other sarcomas, gastrointestinal tumors, and lung cancers. ${ }^{13-15}$

\section{Structure, pharmacology, and preclinical activity}

Entrectinib, also known as RXDX-101 (Figure 1), is a small molecule, which inhibits TRKA, TRKB, TRKC, ROS1, and $A L K$ rearrangements. ${ }^{2,16,17}$ In preclinical studies, entrectinib demonstrated potent antitumor effects in engineered murine or human tumor cell lines and patient-derived xenograft $(\mathrm{PDX})$ tumor models. In vitro, entrectinib potently inhibited TRKA/B/C, ROS1, and $A L K$ at low nanomolar

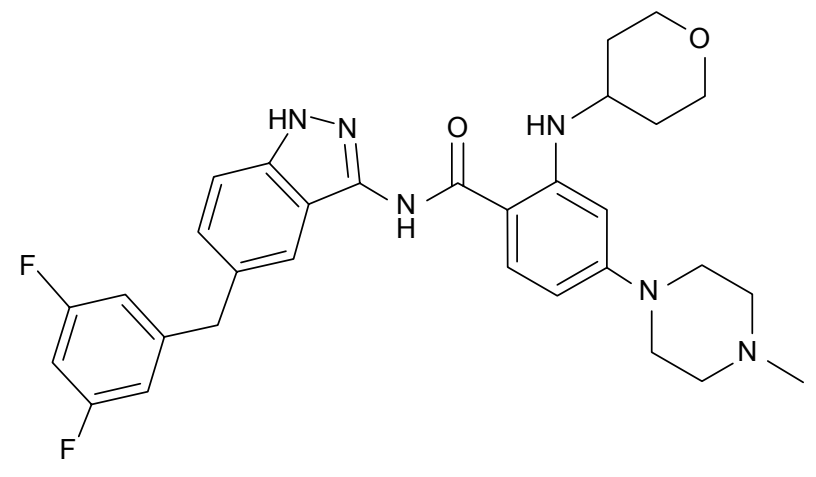

Figure I Chemical structure of entrectinib. ${ }^{18}$ concentrations, with average median inhibitory concentrations (IC50) of 0.002, 0.00057, and 0.0011 $\mu \mathrm{M}$ against TRKA/B/C enzymes, respectively, $0.007 \mu \mathrm{M}$ against ROS1, and 0.019 against ALK. ${ }^{18-20}$ In KM-12, a colorectal cancer cell line, which is driven by a TPM3-NTRK1 gene fusion, entrectinib showed potent anti-proliferative, cell cycle arrest, and apoptotic effects, with the inactivation of downstream genes, such as $A K T, E R K$, and $P L C \gamma 1 .{ }^{16,20}$ The drug also selectively repressed $A L K$-dependent signaling in $A L K$ dependent patient-derived colorectal cancer, lung cancer, ALCL, and neuroblastoma cell lines. ${ }^{16}$ In vivo, entrectinib has displayed anti-tumor activity and induced tumor regression in mouse PDX models of colorectal cancer harboring a TPM3-NTRK1 gene fusion, soft tissue sarcoma with a TPM3-NTRK1 gene fusion, lung cancers with MPRIPNTRK1, ETV6-ROS1, SCD4-ROS1, CD74-ROS1, and ALK fusions, head and neck cancer with an ETV6-NTRK3 gene fusion, and acute myeloid leukemia with an ETV6-NTRK3 gene fusion. Complete tumor regression was observed in Karpas-299 and SR-786 PDX models harboring NPM1-ALK rearrangements. In addition, entrectinib was also found to inhibit tumor growth, delay tumor progression, and cause tumor death in an SY5Y-TRKB-rearranged PDX model of neuroblastoma overexpressing TRKB. When entrectinib was tested in a murine model intracranially injected with the NSCLC tumor cell line NCI-H2228, it inhibited tumor growth and survival was dose-dependent. ${ }^{16-21}$

Entrectinib's pharmacokinetic profile has been well studied in the Phase I setting. All current protocols utilize entrectinib in the fed condition, which is defined as within 30 minutes of meals. Entrectinib is highly protein bound, and in humans, the plasma protein binding is about $99.5 \%$. It is known to readily cross the blood-brain barrier. In mice, exposure of entrectinib for both $\mathrm{C}_{\max }$ and the area under the concentration-time curve in the brain was $\sim 20 \%$ of plasma exposures following a single dose. Time to maximal concentration $\left(\mathrm{T}_{\max }\right)$ was 2-4 hours in the fasted state and appeared to occur later (5-7 hours) in the fed state. Exposures to entrectinib increased linearly across the studied dose ranges. The mean terminal half-life was $\sim 20$ hours in the fed state, which supports once-daily dosing. Entrectinib is mainly metabolized by CYP3A4 with minor contribution from CYP2C9 and CYP1C19. 2,16,18

\section{Safety and tolerability}

In normal cells, proteins of the TRK family are involved in the regulation, differentiation, and apoptosis of neurons. ${ }^{13,22,23}$ The TRKA/B/C are the preferred receptors of growth factors, 
such as NGF, BDNF, and NT-3, as previously described. Germline mutations involving the NTRK1 gene in humans can cause congenital insensitivity to pain and mental retardation. Mice lacking TRKB have a dramatically reduced number of neurons. Knockout models of $B d n f(-/-)$ resulted in animals exhibiting head bobbing, spinning, and hind limb extension during locomotion. Heterozygote Bdnf knockouts develop hyperphagia and obesity. Mice bred with a Trkc (-/-) knockout exhibit abnormal movements and postures, which are most likely caused by deficiency in proprioceptive neurons. . $2,23,24^{2}$

Entrectinib is safe and well tolerated as a single agent. Its toxicity profile has been presented in a study combining 2 Phase I clinical trials (ALKA-372-001 trial and STARTRK-1 study). ${ }^{2}$ Fifty-four patients with previously-treated advanced solid tumors harboring NTRK1/2/3, ROS1, or ALK alterations were included in the ALKA-372-001 dose-escalation study. Sixty of the 119 patients had an NTRK 1/2/3, ROS1, or $A L K$ gene rearrangement. Fifty-three patients had genomic alterations, including point mutations, amplifications, insertions, deletions, and/or copy number variants and 6 patients enrolled in these studies did not have a known NTRK 1/2/3, $R O S 1$, or $A L K$ alteration. ${ }^{2}$ Entrectinib was administered at different dosing schedules (Table 1). All patients in the STARTRK-1 study received entrectinib treatment daily continuously while on the study. A continuous dose of $600 \mathrm{mg}$ daily was then identified as the maximal tolerated dose and recommended Phase II dose (RP2D) in adults. In both studies, dose-limiting toxicities were evaluated during cycle 1 . The drug-related adverse events (AEs) were graded according to the National Cancer Institute Common Terminology Criteria for Adverse Events v4.03. No treatment-related Grade 5 AEs were reported in either trial. The only Grade 4 drug toxicity observed was an eosinophilic myocarditis event on STARTRK-1. The most frequently reported AEs were fatigue/asthenia (46\%), dysgeusia (42\%), paresthesia (29\%), nausea (28\%), myalgia (23\%), diarrhea (19\%), vomiting $(17 \%)$, arthralgia (16\%), dizziness (16\%), constipation $(12 \%)$, and weight gain $(10 \%){ }^{2}$

A similar adverse effect profile was described in an analysis of 203 patients treated at the RP2D dose across 3 clinical studies in adult patients. Most of the AEs were grade 1-2 and reversible. In these 203 patients, treatmentrelated AEs led to dose interruption in $32 \%$ of patients, dose reduction in $19 \%$ of patients, and permanent discontinuation of study treatment in $3 \%$ of patients. ${ }^{25}$ There was no evidence of cumulative toxicity, QTc prolongation, or clinically significant hepatic toxicity ${ }^{2,25}$ (Table 2).

\section{Efficacy}

The clinical activity of entrectinib has been assessed in 4 ongoing clinical trials (Table 1). The combined results from 2 early-phase clinical trials (ALKA-372-001 and STARTRK-1), which included a total of 119 patients were reported in early 2017. Thirty patients whose tumors harbored 1 of the 5 gene fusions of interest (TRKA/B/C, ROS1, and $A L K$ ), who were tyrosine kinase inhibitor (TKI)-naïve, and whose dosing achieved therapeutic exposures consistent with $600 \mathrm{mg}$ entrectinib daily were defined as a "Phase II-eligible population". The results of the activity of entrectinib in patients with ROS1 fusions in ROS1 inhibitor-naïve NSCLC patients enrolled across the STARTRK-2, STARTRK-1, and ALKA-372-001 studies were presented at the International Association for the Study of Lung Cancer 18th World Conference on Lung Cancer ${ }^{2,25}$ (Table 3).

In the subgroup of NTRK-rearranged cancers $(\mathrm{n}=4)$, all patients, with various tumor histologies and fusion types,

Table I Entrectinib clinical trials

\begin{tabular}{|c|c|c|c|}
\hline Study & Patient population & Study design & Dose and schedule \\
\hline ALKA-372-00 I² & $\begin{array}{l}\text { Locally advanced or metastatic cancer } \\
\text { targeting NTRKI, NTRK2, NTRK3, ROSI, } \\
\text { or ALK molecular alterations }\end{array}$ & Phase I basket & $\begin{array}{l}100-1,800 \mathrm{mg} / \mathrm{m}^{2} \\
\text { Schedule } A(n=19) \text { : fasted, } 4 \text { days on and } 3 \text { days off for } \\
2 \text { I of } 28 \text { days } \\
\text { Schedule } B(n=29) \text { : fed, continuous daily dosing for } 28 \text { days } \\
\text { Schedule } C(n=6) \text { : fed, } 4 \text { days on and } 3 \text { days off for } 28 \text { days }\end{array}$ \\
\hline STARTRK-I² & $\begin{array}{l}\text { Locally advanced or metastatic cancer } \\
\text { targeting NTRKI/2/3, ROSI, or ALK } \\
\text { molecular alterations }\end{array}$ & Phase I basket & $\begin{array}{l}100-1,800 \mathrm{mg} / \mathrm{m}^{2} \\
\text { Fed, continuous daily dosing for } 28 \text { days }(n=65)\end{array}$ \\
\hline STARTRK-2 ${ }^{36}$ & $\begin{array}{l}\text { Solid tumors that harbor an } N T R K I / 2 / 3 \text {, } \\
\text { ROSI, or } A L K \text { gene fusion }\end{array}$ & Phase II basket & $\begin{array}{l}600 \mathrm{mg} \\
\text { Fed, continuous daily dosing for } 28 \text { days }\end{array}$ \\
\hline STARTRK-NG ${ }^{26}$ & $\begin{array}{l}\text { Children with recurrent or refractory solid } \\
\text { tumors and primary CNS tumors, with or } \\
\text { without } T R K I / 2 / 3, R O S I \text {, or } A L K \text { fusions }\end{array}$ & Phase I/lb & $\begin{array}{l}250 \mathrm{mg} / \mathrm{m}^{2} \\
\text { Fed, continuous daily dosing for } 28 \text { days }\end{array}$ \\
\hline
\end{tabular}

Abbreviations: ALK, anaplastic lymphoma kinase; NTRK, neurotrophic tyrosine kinase; ROSI, ROS proto-oncogene I; CNS, central nervous system. 
Table 2 Entrectinib safety summary

\begin{tabular}{llll}
\hline & $\begin{array}{l}\text { Most common } \\
\text { treatment- } \\
\text { related adverse } \\
\text { events }\end{array}$ & \multicolumn{2}{l}{$\begin{array}{l}\text { Patients treated at } \\
\text { the RP2D (N=203) }\end{array}$} \\
\cline { 2 - 4 } & $\begin{array}{l}\text { All grades } \\
\text { (\%) }\end{array}$ & $\begin{array}{l}\text { Grade 3 } \\
\text { (\%) }\end{array}$ \\
\hline On-target AEs & Dysgeusia & $78(38)$ & $\mathrm{I}(0.5)$ \\
potentially mediated & Dizziness & $46(23)$ & $\mathrm{I}(0.5)$ \\
by TRK inhibition & Weight increased & $39(19)$ & $10(5)$ \\
& Paresthesia & $32(16)$ & - \\
Other AEs & Fatigue & $59(29)$ & $6(3)$ \\
& Constipation & $47(23)$ & $\mathrm{I}(0.5)$ \\
& Diarrhea & $35(17)$ & $\mathrm{I}(0.5)$ \\
& Nausea & $33(16)$ & - \\
& Myalgia & $27(13)$ & $\mathrm{I}(0.5)$ \\
& Peripheral edema & $25(12)$ & - \\
& Anemia & $23(11)$ & $9(4)$ \\
& Blood creatinine & $22(11)$ & $\mathrm{I}(0.5)$ \\
& increased & & \\
& Vomiting & $22(11)$ & - \\
& Arthralgia & $21(10)$ & $\mathrm{I}(0.5)$ \\
\hline
\end{tabular}

Note: Data from Drilon et al ${ }^{2}$ and Myung-Ju Ahn et al..$^{25}$

Abbreviations: AEs, adverse events; RP2D, recommended Phase II dose; TRK, tropomyosin-related kinase.

benefited from entrectinib. These included patients with glioneuronal tumor (BCAN-NTRK), NSCLC (SQSTM1NTRK1), MASC (ETV6-NTRK3), and colorectal cancer $(L M N A-N T R K 1){ }^{2}$ In addition, in the ongoing dose escalation pediatric entrectinib study, a 20-month-old boy with infantile fibrosarcoma harboring an ETV6-NTRK3 fusion had a significant tumor regression of central nervous system

Table 3 Efficacy in Phase II-eligible adult patients

\begin{tabular}{|c|c|c|}
\hline & $\begin{array}{l}\text { ALKA-372-00 I and } \\
\text { STARTRK-I, ORR } \\
\text { (\%)/PFS (months)/ } \\
\text { OS (months) }\end{array}$ & $\begin{array}{l}\text { ALKA-372-00I, } \\
\text { STARTRK-I and } \\
\text { STARTRK-2, ORR/PFS } \\
\text { (months)/OS (months) }\end{array}$ \\
\hline $\begin{array}{l}\text { Patients with NTRK } \\
\text { fusion-positive solid } \\
\text { tumors }\end{array}$ & $\begin{array}{l}4 / 4(100 \%) / \text { not } \\
\text { reached/not reached }\end{array}$ & Pending \\
\hline $\begin{array}{l}\text { Patients with ROSI } \\
\text { fusion-positive solid } \\
\text { tumors }\end{array}$ & $\begin{array}{l}\text { I2/14 (86\%)/I9/not } \\
\text { reached }\end{array}$ & Pending \\
\hline $\begin{array}{l}\text { Patients with ROSI } \\
\text { fusion-positive lung } \\
\text { cancers (WCLC } \\
2017 \text { update) }\end{array}$ & NA & $25 / 32(78 \%) / 29.6 / \mathrm{NA}$ \\
\hline $\begin{array}{l}\text { Patients with } A L K \\
\text { fusion-positive solid } \\
\text { tumors }\end{array}$ & $\begin{array}{l}4 / 7(57 \%) / 8.3 / \text { not } \\
\text { reached }\end{array}$ & Pending \\
\hline $\begin{array}{l}\text { Patients with } \\
\text { genomic alterations } \\
\text { other than gene } \\
\text { fusions }\end{array}$ & I/59 (I.6\%)/NA/NA & Pending \\
\hline
\end{tabular}

Note: Data from Drilon et al ${ }^{2}$ and Myung-Ju Ahn et al..$^{25}$

Abbreviations: ALK, anaplastic lymphoma kinase; NTRK, neurotrophic tyrosine kinase; ORR, overall response rate; PFS, progression-free survival; ROSI, ROS proto-oncogene I; WCLC, World Conference on Lung Cancer; OS, overall survival; NA, not applicable.
(CNS) metastases and clinical improvement following 1 month of therapy. ${ }^{26}$

Currently, there are no commercially available oral TRK inhibitors. However, in May 2017 and October 2017, entrectinib received the breakthrough designation and priority medicines (PRIME) designation from the US Food and Drug Administraton (FDA) and European Medicines Agency (EMA), respectively, as a treatment for adult and pediatric patients with NTRK-positive solid tumors who have either progressed following prior therapies or who have no further standard treatment options. ${ }^{27,28}$ Both highlighted the need for further development of targeted approaches in this population of unmet need.

Treatment with entrectinib led to an objective response in 12 of 14 evaluable patients (86\%) in the subgroup with ROS1-rearranged tumors, 2 of whom had a complete response. Eleven of those responding had lung cancer while the remaining 3 had melanoma. As of September 2017, 32 ROS1 fusion-positive lung cancer patients, who had no prior exposure to ROS1-targeted therapies, were enrolled across the STARTRK-2, STARTRK-1, and ALKA-372-001 studies. ${ }^{25}$ Responses were observed in 25 patients (ORR $78 \%$ ). The median duration of response was 28.6 months (95\% Cl: 6.8-34.8) and the median PFS was 29.6 months (95\% Cl: 7.7-36.6). Entrectinib demonstrated strong CNS activity in ROS1-rearranged patients with measurable CNS disease at baseline with an intracranial response noted in 5 of 6 patients (ORR 83.3\%). ${ }^{25}$

In the $A L K$-rearranged cancers $(\mathrm{n}=7), 57 \%$ of patients experienced a response with most patients in this group having lung cancer $(\mathrm{n}=5)$. The tumor-agnostic activity of entrecinib in TKI-naïve patients with sensitizing rearrangements in $A L K, R O S 1$, and NTRK led to robust and rapid responses being observed within the first 2 cycles of treatment. With a median duration of follow-up of 15 months, the median PFS has not yet been reached in patients harboring NTRK1/2/3 rearranged tumors and was 19.0 and 8.3 months in patients harboring $R O S 1$ or $A L K$-rearranged malignancies, respectively. The median overall survival has not yet been reached among all evaluable patients. ${ }^{2}$ The potent intracranial antitumor activity of entrectinib was observed among 5 of the 8 $(63 \%)$ evaluable patients who had known primary or metastatic disease involving the brain, which included 4 patients with NTRK1 $(\mathrm{n}=1), \operatorname{ROS} 1(\mathrm{n}=2)$, and $A L K(\mathrm{n}=1)$-rearranged lung cancer and 1 with $A L K$-rearranged colorectal cancer. ${ }^{2}$

The excellent response rate observed in patients harboring the 5 gene fusions of interest was not observed in the 59 patients whose tumors harbored other types of genomic alterations (non-gene fusion events), with a response in only 
1 of 59 patients ( $A L K$ F1245V mutant neuroblastoma; entrectinib was granted orphan drug designation and rare pediatric disease designation for neuroblastoma in December $2014^{29}$ ). Furthermore, no responses were observed in patients who had previously received an ROS1 or ALK inhibitor prior to entrectinib. ${ }^{2}$

\section{Acquired resistance to entrectinib}

In cancers harboring NTRK fusions, like many if not all metastatic oncogene-addicted cancers, relapse will inevitably occur secondary to the selective pressures of targeted therapy leading to acquired resistance. In 1 patient with entrectinibresistant colorectal cancer, 2 acquired resistance mutations (G595R and G667C) in the NTRK1 kinase domain were found in the patient's circulating tumor DNA (ctDNA). ${ }^{30}$ Another case of entrectinib resistance by the NTRK3 G623R kinase domain mutation in MASC was reported..$^{31}$

Two next-generation TRK inhibitors (LOXO-195 and TPX-0005) are being tested in clinic to overcome these recurrent resistance mutations. ${ }^{32,33}$ The first 2 patients with TRK fusion-positive cancers who developed acquired resistance mutations on another first-generation TRK-inhibitor, larotrectinib, received treatment with LOXO-195 and achieved rapid tumor responses and extended overall duration of disease control. ${ }^{33,34}$ When trametinib was added to entrectinib, 1 patient with NTRK3 fusion-positive MASC harboring the solvent front mutation NTRK3 G623R in a post-entrectinib treatment biopsy achieved a $22 \%$ reduction in tumor volume and remained on the combination treatment for 6.7 months. ${ }^{17}$

\section{Future directions and conclusion}

The data presented here show that entrectinib, an orally available and CNS-active pan-TRK, ROS1 and ALK inhibitor, is safe and potent in advanced solid tumors with $N T R K 1 / 2 / 3$, $R O S 1$, or $A L K$ rearrangements.

Entrectinib is a first-generation TRK inhibitor with activity against TRK fusions. The acceptance into the PRIME program of EMA, analogous to the Breakthrough Therapy Designation from the US FDA, further supports the broad potential of entrectinib as a novel treatment for patients with NTRKpositive tumors regardless of age and the site of tumor.

In ROS1-rearranged lung cancers, crizotinib gained approval from both US FDA and EMA in 2016 based on the remarkable efficacy in the Phase I PROFILE 1001 study. ${ }^{10}$ The ORR with crizotinib was $72 \%$ among 50 patients with ROS1-rearranged NSCLC in this trial. The median PFS reached 19.2 months. ${ }^{10}$ Another potent ROS1 inhibitor, ceritinib, was also studied in this patient population. ${ }^{35}$ Thirty-two patients with ROS1-rearranged metastatic lung cancers were treated in a Phase II trial. Among crizotinib-naïve patients, the ORR to ceritinib was $67 \%$ and the median PFS reached 19.3 months. ${ }^{35}$ Compared with crizotinib and ceritinib, the PFS benefit of entrectinib (29.6 months) and its superior intracranial response and side effects profile make this drug attractive as a first-line treatment in ROS1-rearranged lung cancers, assuming that more mature data confirm its efficacy. ${ }^{25}$ Of note, although entrectinib is clinically active in ROS1 inhibitor-naïve ROS1-rearranged lung cancers, the role of entrectinib will likely be much more limited in the crizotinib-resistant setting. In preclinical studies, entrectinib does not show activity against the most common resistant ROS1 mutations, including the gatekeeper mutation, L2026M, and the solvent front mutations, G2032R and D2033N. ${ }^{16,18}$

The role of entrectinib as an ALK inhibitor remains less clear. In the 2 Phase I studies, responses were achieved in 5 different histologies harboring $A L K$ gene alterations, including lung cancers, renal cell carcinoma, cancer of unknown primary, colorectal cancer, and neuroblastoma in both adult and pediatric patients, highlighting a possible niche for the drug outside $A L K$-rearranged lung cancers. Additional clinical trials will help further define the role of entrectinib in cancers with other $A L K$ alterations. ${ }^{2}$

Collectively, data obtained with entrectinib demonstrate that the drug is a viable treatment option for patients with malignancies harboring oncogenic NTRK, ROS1, or ALK fusions. Ongoing and future studies may help to further clarify the best place of therapy of entrectinib.

\section{Acknowledgment}

This research was funded in part through the NIH/NCI Cancer Center Support Grant P30 CA008748.

\section{Disclosure}

AD has received honoraria for advisory board participation from Ignyta, Loxo Oncology, and TP Therapeutics. The authors report no other conflicts of interest in this work.

\section{References}

1. Blume-Jensen P, Hunter T. Oncogenic kinase signalling. Nature. 2001; 411(6835):355-365.

2. Drilon A, Siena S, Ou SI, et al. Safety and antitumor activity of the multitargeted Pan-TRK, ROS1, and ALK inhibitor entrectinib: combined results from two Phase I trials (ALKA-372-001 and STARTRK-1). Cancer Discov. 2017;7(4):400-409.

3. Brodeur GM, Minturn JE, Ho R, et al. Trk receptor expression and inhibition in neuroblastomas. Clin Cancer Res. 2009;15(10):3244-3250.

4. Aisner DL, Nguyen TT, Paskulin DD, et al. ROS1 and ALK fusions in colorectal cancer, with evidence of intratumoral heterogeneity for molecular drivers. Mol Cancer Res. 2014;12(1):111-118.

5. Bergethon $\mathrm{K}$, Shaw AT, Ou SH, et al. ROS1 rearrangements define a unique molecular class of lung cancers. J Clin Oncol. 2012;30(8):863-870. 
6. Malik SM, Maher VE, Bijwaard KE, et al. U.S. Food and Drug Administration approval: crizotinib for treatment of advanced or metastatic non-small cell lung cancer that is anaplastic lymphoma kinase positive. Clin Cancer Res. 2014;20(8):2029-2034.

7. Shaw AT, Gandhi L, Gadgeel S, et al. Alectinib in ALK-positive, crizotinib-resistant, non-small-cell lung cancer: a single-group, multicentre, phase 2 trial. Lancet Oncol. 2016;17(2):234-242.

8. Ou SH, Ahn JS, De Petris L, et al. Alectinib in crizotinib-refractory ALK-rearranged non-small-cell lung cancer: a Phase II global study. J Clin Oncol. 2016;34(7):661-668.

9. Khozin S, Blumenthal GM, Zhang L, et al. FDA approval: ceritinib for the treatment of metastatic anaplastic lymphoma kinase-positive nonsmall cell lung cancer. Clin Cancer Res. 2015;21(11):2436-2439.

10. Shaw AT, Ou SH, Bang YJ, et al. Crizotinib in ROS1-rearranged nonsmall-cell lung cancer. N Engl J Med. 2014;371(21):1963-1971.

11. FDA expands use of Xalkori to treat rare form of advanced non-small cell lung cancer [press release]. 2016. Available from: https://www. fda.gov/newsevents/newsroom/pressannouncements/ucm490329.htm. Accessed June 26, 2018.

12. Snider WD. Functions of the neurotrophins during nervous system development: what the knockouts are teaching us. Cell. 1994;77(5): 627-638.

13. Amatu A, Sartore-Bianchi A, Siena S. NTRK gene fusions as novel targets of cancer therapy across multiple tumour types. ESMO Open. 2016; 1(2):e000023.

14. Vaishnavi A, Capelletti M, Le AT, et al. Oncogenic and drug-sensitive NTRK1 rearrangements in lung cancer. Nat Med. 2013;19(11): 1469-1472.

15. Dogan S, Wang L, Ptashkin RN, et al. Mammary analog secretory carcinoma of the thyroid gland: a primary thyroid adenocarcinoma harboring ETV6-NTRK3 fusion. Mod Pathol. 2016;29(9): 985-995.

16. Ardini E, Menichincheri M, Banfi P, et al. Entrectinib, a Pan-TRK, ROS1, and ALK Inhibitor with Activity in Multiple Molecularly Defined Cancer Indications. Mol Cancer Ther. 2016;15(4): 628-639.

17. Ardini E, Lombardi Borgia A, De Ponti C, et al. Identification and preclinical characterization of NMS-P626, a potent, selective and orally bioavailable TrkA inhibitor with anti-tumor activity in a TrkAdependent colorectal cancer. 22nd AACR-NCI-EORTC symposium on molecular targets and cancer therapeutics. Eur J Cancer Supplements. 2010;8(7):39-40.

18. Menichincheri M, Ardini E, Magnaghi P, et al. Discovery of entrectinib: a new 3-Aminoindazole as a potent Anaplastic Lymphoma Kinase (ALK), c-ros Oncogene 1 Kinase (ROS1), and Pan-Tropomyosin Receptor Kinases (Pan-TRKs) inhibitor. J Med Chem. 2016;59(7):3392-3408.

19. Ardini E, Menichincheri M, Banfi $P$, et al. In vitro and in vivo activity of NMSE-628 against ALK mutations resistant to Xalkori. Mol Cancer Ther. 2011;10(Suppl 1).

20. Anderson D, Ciomei M, Banfi P, et al. Inhibition of Trk-driven tumors by the pan-Trk inhibitor RXDX-101. EJC. 2014;50(Supplement 6):101.

21. Ardini E, Menichincheri M, Banfi P, et al. The ALK inhibitor NMSE628 also potentially inhibits ROS1 and induces tumor regression in ROS-driven models. Cancer Res J. 2013;78(8 Supplement):2092.

22. Arevalo JC, Conde B, Hempstead BI, Chao MV, Martin-Zanca D, Perez P. A novel mutation within the extracellular domain of TrkA causes constitutive receptor activation. Oncogene. 2001;20(10):1229-1234.

Therapeutics and Clinical Risk Management

\section{Publish your work in this journal}

Therapeutics and Clinical Risk Management is an international, peerreviewed journal of clinical therapeutics and risk management, focusing on concise rapid reporting of clinical studies in all therapeutic areas, outcomes, safety, and programs for the effective, safe, and sustained use of medicines. This journal is indexed on PubMed Central, CAS,
23. Crowley C, Spencer SD, Nishimura MC, et al. Mice lacking nerve growth factor display perinatal loss of sensory and sympathetic neurons yet develop basal forebrain cholinergic neurons. Cell. 1994;76(6):1001-1011.

24. Skaper SD. The biology of neurotrophins, signalling pathways, and functional peptide mimetics of neurotrophins and their receptors. CNS Neurol Disord Drug Targets. 2008;7(1):46-62.

25. Myung-Ju Ahn BCC, Siena S, Drilon A, et al. Entrectinib in patients with locally advanced or metastatic ROS1 fusion-positive non-small cell lung cancer (NSCLC). IASLC 18th World Conference on Lung Cancer; 2017; Yokohama, Japan.

26. Rangaraju S, Li G, Christiansen J, Hornby Z, Multani P, Esquibel V, Maneval EC. TRTH-10. Pediatric Phase 1/1B Study of entrectinib in patients with primary brain tumors, neuroblastoma, and NTRK, ROS1, or ALK Fusions. Neuro-Oncology, 2017;19(4):iv53.

27. Ignyta Receives FDA Orphan Drug Designation for Entrectinib for Treatment of NTRK Fusion-Positive Solid Tumors [press release]. 2017. Available from: https://www.businesswire.com/news/ home/20170710005477/en/. Accessed June 26, 2018.

28. Ignyta Receives European Medicines Agency Prime Designation for Entrectinib in NTRK Fusion-Positive Solid Tumors [press release]. 2017. Available from: https://www.businesswire.com/news/ home/20171017005620/en/Ignyta-Receives-European-MedicinesAgency-Prime-Designation. Accessed June 26, 2018.

29. Ignyta Receives Orphan Drug Designation and Rare Pediatric Disease Designation from FDA for Entrectinib for the Treatment of Neuroblastoma [press release]. 2014. Available from: https://www.fda.gov/ downloads/AdvisoryCommittees/CommitteesMeetingMaterials/Drugs/ OncologicDrugsAdvisoryCommittee/UCM508677.pdf. Accessed June 26, 2018.

30. Russo M, Misale S, Wei G, et al. Acquired resistance to the TRK inhibitor entrectinib in colorectal cancer. Cancer Discov. 2016;6(1):36-44.

31. Drilon A, Li G, Dogan S, et al. What hides behind the MASC: clinical response and acquired resistance to entrectinib after ETV6-NTRK3 identification in a mammary analogue secretory carcinoma (MASC). Ann Oncol. 2016;27(5):920-926.

32. Cui JJ, Zhai D, Deng W, et al. TPX-0005, a novel ALK/ROS1/TRK inhibitor, effectively inhibited a broad spectrum of mutations including solvent front ALK G1202R, ROS1 G2032R and TRKA G595R mutants 28 EORTC - NCI - AACR Symposium on Molecular Targets and Cancer Therapeutics 2016; Munich, Germany.

33. Drilon A, Nagasubramanian R, Blake JF, et al. A next-generation TRK kinase inhibitor overcomes acquired resistance to prior TRK kinase inhibition in patients with TRK fusion-positive solid tumors. Cancer Discov. 2017;7(9):963-972.

34. Hyman DM, Laetsch TW, Kummar S, et al. The efficacy of larotrectinib (LOXO-101), a selective tropomyosin receptor kinase (TRK) inhibitor, in adult and pediatric TRK fusion cancers. J Clin Oncol. 2017;35 (no. 18_suppl).

35. Lim SM, Kim HR, Lee JS, et al. Open-label, multicenter, Phase II study of ceritinib in patients with non-small-cell lung cancer harboring ROS1 rearrangement. J Clin Oncol. 2017;35(23):2613-2618.

36. Alexander Drilon KKS, Liu SV, Cho BC, et al. STARTRK-2: A global phase 2, open-label, basket study of entrectinib in patients with locally advanced or metastatic solid tumors harboring TRK, ROS1, or ALK gene fusions. AACR Annual Meeting 2017; April 1-5, 2017, 2017; Washington, DC.

\section{Dovepress}

EMBase, Scopus and the Elsevier Bibliographic databases. The manuscript management system is completely online and includes a very quick and fair peer-review system, which is all easy to use. Visit http://www.dovepress.com/testimonials.php to read real quotes from published authors. 